\title{
Measurement of flow through perfused bronchial segments: optimization of flow head resistance
}

\author{
P.K. McFawn, M.P. Sparrow, H.W. Mitchell
}

\begin{abstract}
Measurement of flow through perfused bronchial segments: optimization of flow head resistance. P.K. McFawn, M.P. Sparrow, H.W. Mitchell. (C)ERS Journals Ltd 1995.

ABSTRACT: Techniques for measuring flow, for example through perfused bronchial segments, frequently use a flow head as the sensing device. The sensitivity of these instruments to changes in airway resistance is dependent on the flow head resistance. This study aims to quantify the effect of flow head resistance on sensitivity and flow, allowing optimization of flow head resistance.

A mathematical model of the perfused bronchial segment preparation was constructed and used to explore the effect of flow head resistance on sensitivity. The model's assumptions were experimentally tested using segments of pig bronchus, perfused through the lumen with Krebs solution.

The model suggests a complex relationship between flow head resistance and sensitivity that has a distinct maximum when approximately half of the total resistance is present in the flow head. Furthermore, the maximum sensitivity was found to be proportional to the resting flow. Regression between experimentally derived sensitivities and modelled predictions was linear, with a correlation coefficient of 0.93 .

We have defined the optimum recording conditions for study of flow through isolated bronchial segments.
\end{abstract}

Eur Respir J., 1995, 8, 161-166.
Dept of Physiology, The University of Western Australia, Nedlands, Australia.

Correspondence: P.K. McFawn

Dept of Physiology

The University of Western Australia

Nedlands 6009

Australia

Keywords: Airway narrowing flow heads

perfused bronchial segments pneumotachographs

Received: 30 September 1993

Accepted after revision September 211994

This research was supported by the Sudden Infant Death Syndrome (SIDS) Foundation of Western Australia and National SIDS Council of Australia.
In vivo, bronchoconstriction is dependent not only on smooth muscle force production but also on the mechanical, geometrical and morphological properties of the intact airway wall [1-3]. Mechanical properties of the airway wall affect the load that the airway smooth muscle contracts against and the degree of the muscle shortening [4]. Airway narrowing may be affected by the geometrical arrangement of the smooth muscle; continuous or discontinuous, spiralled or circular [5]. Several aspects of airway morphology may influence bronchoconstriction, such as invagination of the mucosa, into the bronchial lumen [1], wall area [1, 6], and airway size [7]. Hence, many factors present in the intact airway wall other than contractile force can affect airway narrowing.

The above mechanical and morphological properties are not present in isolated strips of airway normally used to study airway function in vitro. Narrowing and flow through intact airways has largely been studied using mathematical models of bronchi $[1,5,8]$. MitcheLL and co-workers [7, 9-11] and others [12] have reported on a preparation that allows the measurement of flow through perfused bronchial segments, in vitro, preserving the structure of the airway wall.

Direct measurement of flow through isolated airways allows current theoretical relationships between muscle shortening and airflow [1, 5, 8] - including some with direct clinical importance - to be tested. For example, the mechanisms hypothesized by JAMES et al. [6] to explain asthmatic hyperresponsiveness would also produce hyperresponsiveness in perfused bronchi in vitro, but not in airway strips. The understanding of other diseases may also be improved through better knowledge of the function of the airway wall. MARTINEZ [13], for example, has hypothesized that peripheral airway obstruction, caused in part by the infant's airway geometry, may be an important event in the sudden infant death syndrome.

The perfused bronchus apparatus measures flow by recording the pressure drop across a flow head of known resistance, as does a pneumotachograph [10]. Respirologists appreciate that pneumotachograph resistance must be high enough to produce a signal, but low enough not to inhibit flow. When low flow rates must be accurately measured - as with perfused bronchi - the choice of flow head resistance is critically important. Hence, there is a need for a method of determining the best flow head or pneumotachograph resistance for a particular application.

The aim of this investigation was to develop a mathematical model of the effect of flow head resistance on flow measurements. This model was then used to determine the flow head resistance for optimum recording sensitivity. The effects that driving pressure and other resistances present in the preparation have on sensitivity was also determined. Assumptions of the mathematical model were experimentally tested using the perfused bronchial segment preparation as an experimental model. Finally, sensitivities predicted from the mathematical model were validated against estimates experimentally derived from perfused bronchi. 
a)

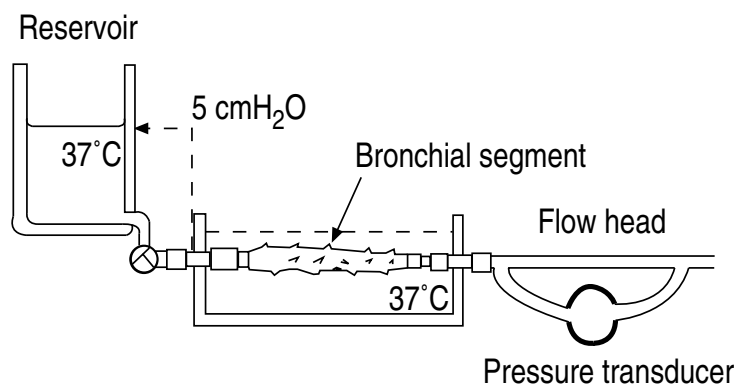

b)

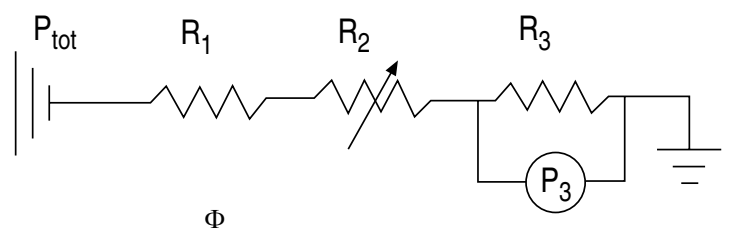

Fig. 1. - a) Perfused bronchial segment preparation showing the reservoir, bronchial segment, flow head and differential pressure transducer. b) Equivalent circuit diagram showing the variables used in the model: driving pressure (Ptot), system resistance $\left(\mathrm{R}_{1}\right)$, airway resistance $\left(\mathrm{R}_{2}\right)$, flow head resistance $\left(\mathrm{R}_{3}\right)$, flow head pressure drop $\left(\mathrm{P}_{3}\right)$ and flow $(\Phi)$.

\section{Model}

We consider the perfused bronchial segment preparation in terms of the equivalent circuit diagram in figure 1. The bronchial segment is represented by the variable resistance $\left(R_{2}\right)$, the flow head by resistance $\left(R_{3}\right)$, all other system resistances (e.g. reservoirs, taps, cannula, etc.) by $\left(\mathrm{R}_{1}\right)$, and the driving pressure by (Ptot).

Assuming that resistance is independent of driving pressure then:

$$
\mathrm{P}=\Phi \mathrm{R} \quad \text { (assumption 1) }
$$

Where, $\mathrm{P}=$ pressure, $\Phi=$ flow, and $\mathrm{R}=$ resistance. Hence:

$$
\mathrm{P}_{3}=\Phi \mathrm{R}_{3}
$$

Thus, the pressure drop across the flow head $\left(\mathrm{P}_{3}\right)$ is the product of the flow head resistance $\left(R_{3}\right)$ and flow rate $(\Phi)$. Increasing flow head resistance $\left(\mathrm{R}_{3}\right)$ will produce a greater flow head pressure drop $\left(\mathrm{P}_{3}\right)$ and a higher measurable signal for any given flow rate $(\Phi)$. However, a high value of $\mathrm{R}_{3}$ will reduce the flow rate for any given driving pressure (Ptot) (fig. 2) as:

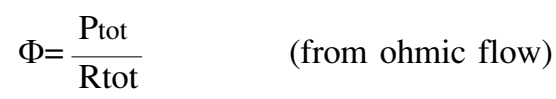

Where, Rtot=total resistance.

$$
\text { Rtot } \left.=\mathrm{R}_{1}+\mathrm{R}_{2}+\mathrm{R}_{3} \quad \text { (assumption } 2\right)
$$

Therefore:

$$
\Phi=\frac{\text { Ptot }}{R_{1}+R_{2}+R_{3}}
$$

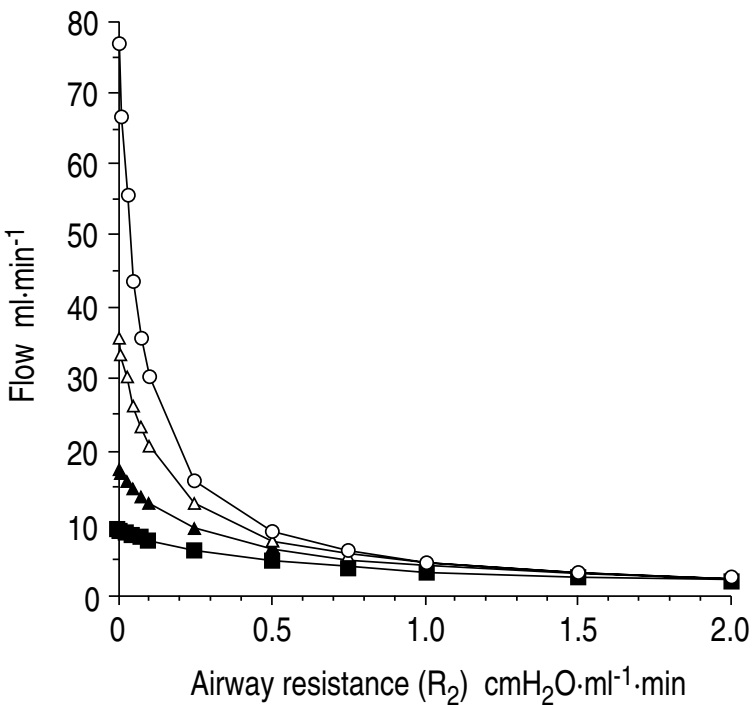

Fig. 2. - Plot of model equation (2) showing flow (Ф) versus airway resistance $\left(R_{2}\right)$ for a range of flow head resistances $\left(R_{3}\right)$. Values used for driving pressure $\left(\mathrm{Ptot}=5 \mathrm{cmH}_{2} \mathrm{O}\right)$ and system resistance $\left(\mathrm{R}_{1}=0.04\right.$ $\left.\mathrm{cmH}_{2} \mathrm{O} \cdot \mathrm{ml}^{-1} \cdot \mathrm{min}\right)$ were close to those measured in perfused bronchial segments. $\longrightarrow-$ - $; \mathrm{R}_{3}=0.025 ;-\triangle-: \mathrm{R}_{3}=0.1 ; \square: \mathrm{R}_{3}=0.25$; $\because: \mathrm{R}_{3}=0.5$.

Equation (2) implies that the change in flow $(\Phi)$ for a given change in airway resistance $\left(R_{2}\right)$ is dependent on the flow head $\left(R_{3}\right)$ and other system $\left(R_{1}\right)$ resistance. Hence, high resistances in series with the airway will be rate limiting and will mask the biological response.

Flow head pressure drop $\left(\mathrm{P}_{3}\right)$, the signal directly measured by the apparatus, can be related to airway resistance $\left(\mathrm{R}_{2}\right)$, the biological variable under investigation, by combining equations (1) and (2):

$$
\mathrm{P}_{3}=\frac{\text { Ptot } \mathrm{R}_{3}}{\mathrm{R}_{1}+\mathrm{R}_{2}+\mathrm{R}_{3}}
$$

Differentiating equation (3) with respect to $R_{2}$ gives the rate of change in $\mathrm{P}_{3}$ (the measured variable) with respect to change in airway resistance $\left(R_{2}\right)$.

$$
\frac{\partial \mathrm{P}_{3}}{\partial \mathrm{R}_{2}}=\frac{-\mathrm{Ptot}_{3}}{\left(\mathrm{R}_{1}+\mathrm{R}_{2}+\mathrm{R}_{3}\right)^{2}}
$$

The value $\partial \mathrm{P}_{3} / \partial \mathrm{R}_{2}$ is the sensitivity of the apparatus, i.e., the change in the measured pressure drop $\left(\mathrm{P}_{3}\right)$ with respect to the change in airway resistance $\left(R_{2}\right)$ (sensitivity $\left(\partial \mathrm{P}_{3} / \partial \mathrm{R}_{2}\right)$ is negative as both $\Phi$ and $\mathrm{P}_{3}$ fall as the airway resistance $\left(R_{2}\right)$ rises). Apparatus sensitivity is directly proportional to pressures (Ptot) and inversely proportional to system resistance $\left(\mathrm{R}_{1}\right)$.

Whilst driving pressure and system resistance have simple effects on sensitivity, the relationship between sensitivity and flow head resistance is complex. Figure 3 illustrates the effect of flow head resistance $\left(\mathrm{R}_{3}\right)$ on sensitivity $\left(\partial \mathrm{P}_{3} / \partial \mathrm{R}_{2}\right)$ (calculated from equation (4)) for a number of airway resistances $\left(R_{2}\right)$ typical of relaxed bronchial segments. The most prominent feature of figure 3 is the pronounced turning point, where sensitivity $\left(\partial \mathrm{P}_{3} / \partial \mathbf{R}_{2}\right)$ is maximized. This implies that there is a flow 


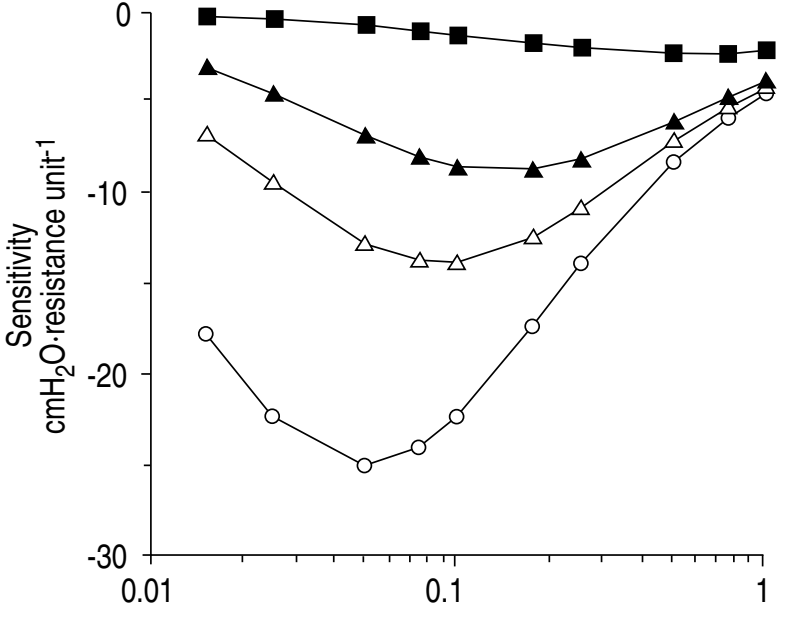

Flow head resistance $\mathrm{cmH}_{2} \mathrm{O} \cdot \mathrm{ml}^{-1} \cdot \min$

Fig. 3. - Plot of model equation (4) showing apparatus sensitivity $\left(\partial \mathrm{P}_{3} / \partial \mathrm{R}_{2}\right)$ versus flow head resistance $\left(\mathrm{R}_{3}\right)$ for a range of airway resistances $\left(\mathrm{R}_{2}\right)$. For driving pressures (Ptot) and system resistance $\left(\mathrm{R}_{1}\right)$ see legend to figure 2. $\multimap-: \mathrm{R}_{2}=0.01 ; \multimap-: \mathrm{R}_{2}=0.05$; $\simeq: \mathrm{R}_{2}=0.1 ; \square: \mathrm{R}_{2}=0.5$.

head resistance $\left(R_{3}\right)$ that gives maximum sensitivity $\left(\partial \mathrm{P}_{3} / \partial \mathbf{R}_{2}\right)$ for each value of airway resistance $\left(\mathrm{R}_{2}\right)$. The flow head resistance that gives maximum sensitivity for a given airway resistance can be found by taking second derivatives of equation (4) (with respect to $R_{3}$ ) and equating to zero:

$$
\begin{gathered}
\frac{\partial^{2} \mathrm{P}_{3}}{\partial \mathrm{R}_{2} \mathrm{R}_{3}}=\frac{\mathrm{d}}{\mathrm{dR}_{3}} \quad\left[-\mathrm{P}_{\mathrm{T}} \mathrm{R}_{3}\left(\mathrm{R}_{1}+\mathrm{R}_{2}+\mathrm{R}_{3}\right)^{-2}\right]=0 \\
\Rightarrow \quad \frac{2 \mathrm{P}_{\mathrm{T}} \mathrm{R}_{3}}{\left(\mathrm{R}_{1}+\mathrm{R}_{2}+\mathrm{R}_{3}\right)^{3}}=\frac{\mathrm{P}_{\mathrm{T}}}{\left(\mathrm{R}_{1}+\mathrm{R}_{2}+\mathrm{R}_{3}\right)^{2}} \\
\mathrm{R}_{3}=\mathrm{R}_{1}+\mathrm{R}_{2}
\end{gathered}
$$

In general, the flow head that gives maximum sensitivity $\left(\partial \mathrm{P}_{3} / \partial \mathrm{R}_{2}\right)$ for a given airway will have a resistance $\left(\mathrm{R}_{3}\right)$ equal to the sum of airway $\left(R_{2}\right)$ and system $\left(R_{1}\right)$ resistances.

Figure 3 shows that the depth as well as position of the turning point is dependent on airway resistance, implying that maximum sensitivity will be different for different airways. Maximum theoretically achievable sensitivity can be found by substituting equation (5) into equation (4) and setting $R_{1}$ to zero:

$$
\frac{\partial \mathrm{P}_{3}}{\partial \mathrm{R}_{2 \max }}=\frac{-\mathrm{P}_{\mathrm{T}}}{4 \mathrm{R}_{2}}
$$

Thus, the maximum sensitivity achievable by a pneumotachograph apparatus is dependent on driving pressure and airway resistance.

So far, the model has only dealt with a constant pressure flow source, such as gravity feed. The model can easily be extended to include a semi-sinusoidal pressure source, such as the ventilation of spontaneously breathing animals. If the driving pressure (Ptot) is sinusoidal, then equations similar to (1)-(4) but containing sine terms, can be developed using the same methods as for the constant pressure case. The sine terms of these equations cancel during the derivation of equation (5), leaving equations (5) and (6) unchanged by using a sinusoidal pressure source.

\section{Methods}

Lungs were removed from freshly slaughtered pigs and segments of main stem bronchus (35 mm long and 2.5 $\mathrm{mm}$ internal diameter (ID) at the distal end) dissected free of parenchyma, as described by Mitchell and coworkers [9]. Bronchial segments were cannulated and mounted in the perfused segment apparatus described by Sparrow and Mitchell [10] (fig. 1). Airway segments were bathed in Krebs solution (heated to $37^{\circ} \mathrm{C}$ ) and the segment lumen perfused with Krebs from a reservoir. The driving pressure (Ptot) was set by the height of the Krebs column in the reservoir, this was normally $5 \mathrm{~cm}$. A custom-built flow head $\left(\mathrm{R}_{3}\right)$ was placed downstream of the segment and the flow head pressure drop $\left(\mathrm{P}_{3}\right)$ measured with a differential pressure transducer (Motorola MPX10DP). Flow rate $(\Phi)$ through the segment could then be determined as it is with pneumotachographs, or by collecting perfusate over a known time.

System resistance $\left(R_{1}\right)$ was measured by removing the flow head and replacing the bronchial segment with 5 $\mathrm{mm}$ ID tubing. Flow head resistance $\left(\mathrm{R}_{3}\right)$ was estimated by measuring resistance with the flow head connected and subtracting the system resistance $\left(R_{1}\right)$. Resistance of bronchial segments $\left(R_{2}\right)$ was similarly estimated. In a limited number of experiments, bronchial segment resistance was estimated by measuring the pressure drop across the airway using side ports on the cannula.

Electrical field stimulation (EFS) from a Grass S44 stimulator ( $70 \mathrm{~V}, 1 \mathrm{~ms}$ pulse width) was used to generate frequency response curves in bronchial segments. Drug responses were generated by the addition of acetylcholine or carbachol (when a prolonged contraction was required) to the bathing solution.

\section{Drugs and solutions}

The Krebs solution used had the following composition (in $\mathrm{mM}$ ): $121 \mathrm{NaCl}, 5.4 \mathrm{KCl}, 1.2 \mathrm{MgSO}_{4}, 1.2$ $\mathrm{NaH}_{2} \mathrm{PO}_{4}, 25 \mathrm{NaHCO}_{3}, 11.5$ glucose, $2.5 \mathrm{CaCl}_{2}$. The solution was aerated continually with $5 \% \mathrm{CO}_{2}$ and $95 \%$ $\mathrm{O}_{2}$. The drugs used were carbamylcholine chloride (carbachol Sigma) and acetylcholine chloride (Sigma). All drugs were dissolved in distilled water and diluted with Krebs solution.

\section{Statistics and analysis}

Results are reported as mean \pm standard error. Significance between treatments was established using analysis of variance (ANOVA) with Newman-Keuls post hoc test. Correlation coefficients ( $\mathrm{r}$ ), coefficients of determination $\left(\mathrm{r}^{2}\right)$ and lines of best fit (by method of least squares) were calculated for linear relationships. Calculation of derived data (such as apparatus sensitivity) and mathematical modelling was carried out using Microsoft Excel. 


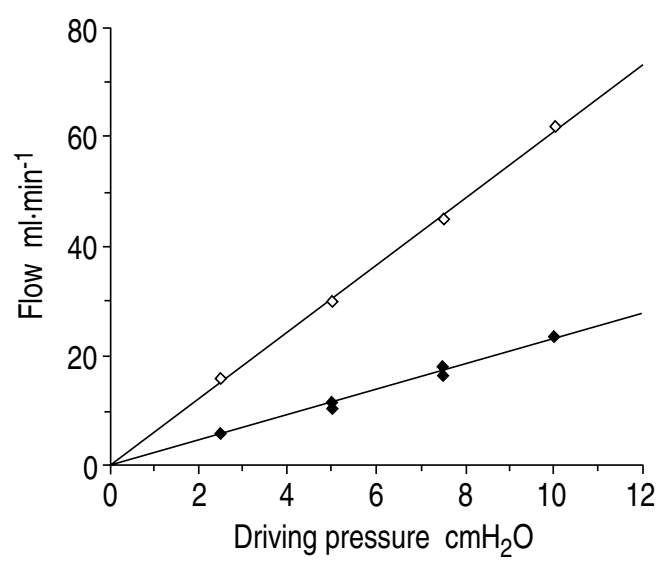

Fig. 4. - Effect of driving pressure (Ptot) on flow (Ф) through a representative bronchial segment, before and after contraction with $10^{-6} \mathrm{M}$ carbachol. Over the pressure range from $0-10 \mathrm{cmH}_{2} \mathrm{O}$ flow was linearly dependent on driving pressure. $\diamond$ :relaxed; $\bullet$ : contracted.

\section{Results}

\section{Testing model assumptions}

Carbachol challenge $\left[10^{-6} \mathrm{M}\right]$ approximately halved flow, with total resistance rising from $0.17 \pm 0.01 \mathrm{cmH}_{2} \mathrm{O} \cdot \mathrm{ml}^{-1} \cdot \mathrm{min}$ $(\mathrm{n}=9)$ in relaxed segments to $0.51 \pm 0.09 \mathrm{cmH}_{2} \mathrm{O} \cdot \mathrm{ml}^{-1} \cdot \mathrm{min}$ after contraction. Flow was linearly dependent on driving pressure (fig. 4) both for relaxed $\left(r^{2}=0.99 \pm 0.01 ; n=9\right)$ and contracted segments $\left(r^{2}=0.97 \pm 0.03\right)$. This indicates that the resistance of the preparation was independent of perfusion pressure over the range tested.

Model equation (1) predicts that pressure drop across the flow head $\left(\mathrm{P}_{3}\right)$ is linearly dependent on flow $(\Phi)$, with a slope equal to the flow head resistance $\left(\mathrm{R}_{3}\right)$. The measured relationship between flow head pressure drop $\left(\mathrm{P}_{3}\right)$ and flow $(\Phi)$ was linear $\left(\mathrm{r}^{2}=0.96\right)$ for 10 bronchial segments, each of which was challenged with a range of acetylcholine doses. This relationship had a slope of $0.058 \pm 0.002 \mathrm{cmH}_{2} \mathrm{O} \cdot \mathrm{ml}^{-1} \cdot \mathrm{min}$, close to the measured flow head resistance of $0.046 \pm 0.002 \mathrm{cmH}_{2} \mathrm{O} \cdot \mathrm{ml}^{-1} \cdot \mathrm{min}$.

From the model (equation (2), fig. 2) flow ( $\Phi)$ should be inversely proportional to bronchial segment resistance $\left(R_{2}\right)$. Measured values of flow and segment resistance from 13 airways, each of which was contracted with a range of acetylcholine doses, are plotted in figure 5 . Superimposed on the data is a plot of equation (2) from the model using measured values of system $\left(R_{1}=0.071\right.$ $\left.\mathrm{cmH}_{2} \mathrm{O} \cdot \mathrm{ml}^{-1} \cdot \mathrm{min}\right)$ and flow head $\left(\mathrm{R}_{3}=0.046 \mathrm{cmH}_{2} \mathrm{O} \cdot \mathrm{ml}^{-1} \cdot \mathrm{min}\right)$ resistance. An extremely good fit was obtained between the predicted and real data.

\section{Effect of varying flow head resistance on apparatus sensitivity}

Apparatus sensitivity $\left(\partial \mathrm{P}_{3} / \partial \mathrm{R}_{2}\right)$ was estimated and compared to predictions from the model (see model equation (4)). Sensitivity $\left(\partial \mathrm{P}_{3} / \partial \mathrm{R}_{2}\right)$ was estimated by dividing change in flow head pressure drop $\left(\mathrm{P}_{3}\right)$ by change

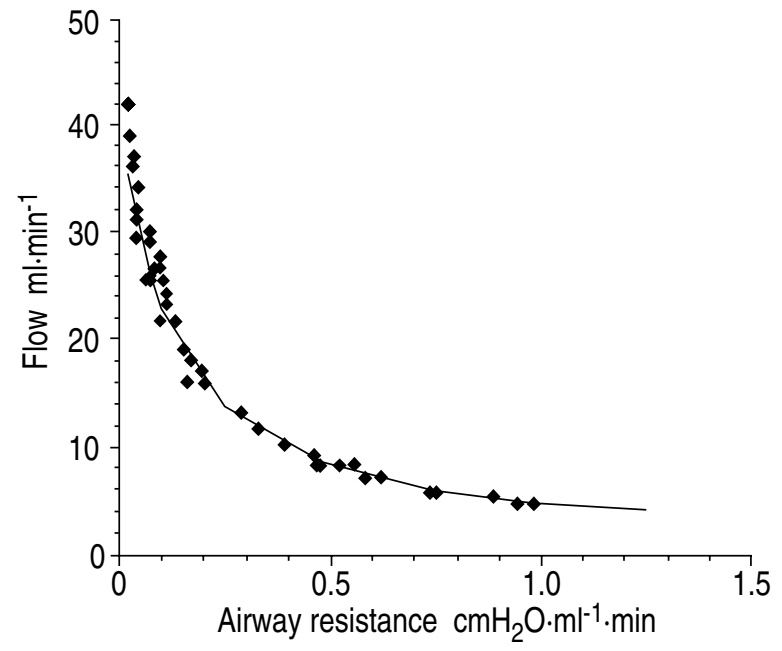

Fig. 5. - Scatter plot of pooled data from 13 bronchial segments, each of which was challenged with a range of acetylcholine dose, showing flow $(\Phi)$ (measured by collecting perfusate) versus airway resistance $\left(\mathrm{R}_{2}\right)$ (measured by connecting the pressure transducer to side ports on the segment cannula). The line through the figure is a plot of equation (4) from the model using the measured values of system $\left(R_{1}=0.071\right.$ $\left.\mathrm{cmH}_{2} \mathrm{O} \cdot \mathrm{ml}^{-1} \cdot \mathrm{min}\right)$ and flow head $\left(\mathrm{R}_{3}=0.046 \mathrm{cmH}_{2} \mathrm{O} \cdot \mathrm{ml}^{-1} \cdot \mathrm{min}\right)$ resistance.

in calculated bronchial segment resistance $\left(\mathrm{R}_{2}\right)$ (see model). Predicted sensitivities were calculated from equation (4) using the value of flow head $\left(\mathrm{R}_{3}\right)$ and system $\left(\mathrm{R}_{1}\right)$ resistance determined for each experiment. The regression line of measured to predicted sensitivity (fig. 6) had a correlation coefficient of 0.93 , demonstrating an extremely strong relationship. The slope of the regression line was $1.3 \pm 0.04$, higher than the expected unity. This discrepancy could result from a systematic underestimation of airway resistance.

Effect of changing flow head resistance on the response of bronchial segments is illustrated in figure 7. Flow reduction to EFS was greatly diminished when the high resistance $\left(\mathrm{R}_{3}=0.90 \mathrm{cmH}_{2} \mathrm{O} \cdot \mathrm{ml}^{-1} \cdot \mathrm{min}, 1 \mathrm{~mm}\right.$ ID) flow head was used in place of a low resistance $\left(R_{3}=0.05\right.$

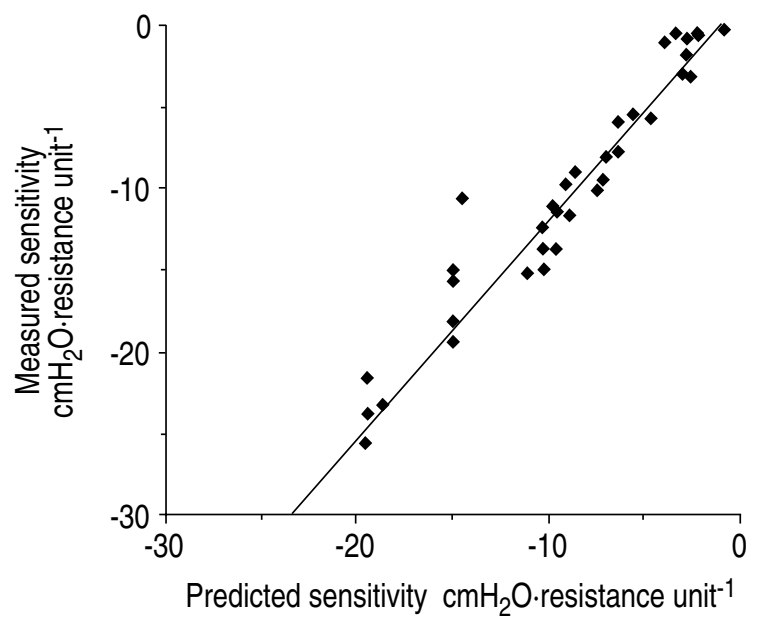

Fig. 6. - Measured apparatus sensitivity $\left(\partial \mathrm{P}_{3} / \partial \mathrm{R}_{2}\right)$ versus predicted apparatus sensitivity $\left(\partial \mathrm{P}_{3} / \partial \mathrm{R}_{2}\right)$ derived from equation (5) in the model $(\mathrm{r}=0.93 ; \beta=1.3 \pm 0.04)$. Apparatus sensitivity $\left(\partial \mathrm{P}_{3} / \partial \mathrm{R}_{2}\right)$ was expressed as the change in flow head pressure drop $\left(\partial \mathrm{P}_{3}\right)$ divided by the change in airway resistance $\left(\partial R_{2}\right)$. 


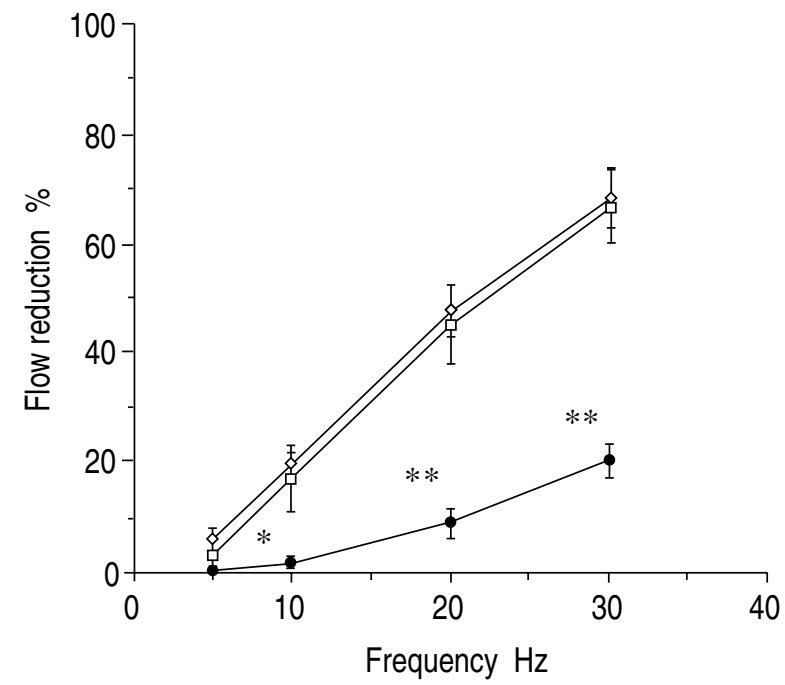

Fig. 7. - Frequency response curves for electrical field stimulated $(1 \mathrm{~ms}, 60 \mathrm{~V})$ bronchial segments with high and low resistance flow heads $(n=5)$. Response is expressed as the percentage reduction in flow during stimulation. Data are presented as mean \pm SEM. Significance, $*: \mathrm{p}<0.05$; $* *: \mathrm{p}<0.01$. Frequency response curves were first obtained using a low resistance $2.15 \mathrm{~mm}$ internal diameter (ID) flow head ( $>$ ); which was changed to a high resistance $1 \mathrm{~mm}$ flow head (—— $)$; and finally back to the original 2.15 mm ID flow head ( $\square$ - $)$.

$\mathrm{cmH}_{2} \mathrm{O} \cdot \mathrm{ml}^{-1} \cdot \min , 2.15 \mathrm{~mm}$ ID) flow head $(\mathrm{n}=5 ; \mathrm{p}<0.01)$. The gradient of the curve in figure 7 for the low resistance flow head was about 2.5, and approximately 0.81 for the high resistance flow head. Replacement of the high resistance flow head with the original flow head returned the response to its previous level. Hence, the apparent responsiveness of the bronchial segment was strongly affected by flow head resistance.

\section{Discussion}

Two mathematical assumptions were made in the model: that resistance is independent of driving pressure and series resistances are additive. Flow through relaxed and partially contracted segments was linearly dependent on driving pressure, validating equation (1) and the first assumption of the model. Independence of resistance and pressure has previously been reported for both porcine [9] and human airways [12]. The good fit between measured and predicted flow for varying airway resistances validates equation (2) and the model's second assumption (i.e. series resistances are additive).

An extremely high correlation was found between measured and predicted values of apparatus sensitivity $\left(\partial \mathrm{P}_{3} / \partial \mathbf{R}_{2}\right)$. However, measured sensitivity was higher than predicted. This may be due to an underestimation of airway resistance producing an overestimation of sensitivity. Alternatively, sensitivities predicted by the model are for infinitesimally small changes in airway resistance, whereas finite changes in airway resistance were used to estimate sensitivity from experimental data. The extremely high correlation coefficient of figure 6 demonstrates that the model is useful for predicting the behaviour of the real apparatus.
One of the model's most significant results was quantifying the attenuation of flow $(\Phi)$ and sensitivity $\left(\partial \mathrm{P}_{3} / \partial \mathrm{R}_{2}\right)$ by system $\left(\mathrm{R}_{1}\right)$ and flow head $\left(\mathrm{R}_{3}\right)$ resistance. Equation (4) shows that apparatus sensitivity is inversely proportional to the square of the total resistance, so that resistance in the apparatus will attenuate the measured response and underestimate the extent of narrowing. Attenuation was observed experimentally (fig. 7) where a high resistance flow head reduced the apparent response of the bronchial segments to EFS. This attenuation effect is applicable to any instrument used to measure flow, whether or not a flow head is used.

Pneumotachographs and the perfused bronchial segment apparatus use flow head resistance $\left(\mathrm{R}_{3}\right)$ to measure flow $(\Phi)$, and a reduction in flow head resistance $\left(\mathrm{R}_{3}\right)$ produces a proportional reduction in signal strength. Hence, extra resistance is added to generate a signal and some attenuation of the response (flow reduction) will be caused by the flow head resistance. The most sensitive flow head will give the greatest signal for the least attenuation of response, i.e., the largest change in pressure drop for a given change in airway resistance. The model states that this will occur when the flow head resistance is equal to that from all other sources (equation (5)). Equation (5) applies both to the in vitro perfused bronchus preparation and to pneumotachographs used to measure ventilation in vivo.

Equation (6) predicts that even with optimum flow head resistance and no other system resistances, apparatus sensitivity would be limited by low driving pressure and high airway resistance. Thus, sensitivity will be highest for preparations with high flow rates. During tidal breathing even small animals have flow rates an order of magnitude higher than those through isolated bronchi. Hence, pneumotachographs used in clinical and experimental procedures have comparatively few problems with sensitivity.

The limitations placed on sensitivity by flow head resistance are not present in some alternative methods for measuring flow. HuLSMANN et al. [12] have recently reported the use of electromagnetic blood flow sensors to measure flow through isolated bronchi. However, the model indicates that the output of any type of flow sensor will be subject to attenuation if a high system resistance is present in the experimental apparatus, such as at cannulae.

\section{References}

1. Moreno RH, Hogg JC, Paré PD. Mechanics of airway narrowing. Am Rev Respir Dis 1986; 133: 1171-1180.

2. Jiang H, Stephens NL. Contractile properties of bronchial smooth muscle with and without cartilage. J Appl Physiol 1990; 69: 120-126.

3. Sparrow MP, McFawn PK, Omari TI, Mitchell HW. Activation of smooth muscle in the airway wall, force production, and airway narrowing. Can J Physiol Pharmacol 1992; 70: 607-614.

4. Ishida K, Paré PD, Blogg T, Schellenberg RR. Effects of elastic loading on porcine trachealis muscle mechanics. J Appl Physiol 1990; 69: 1033-1039.

5. Bates JHT, Martin JG. A theoretical study of the effect 
of ASM orientation on bronchoconstriction. J Appl Physiol 1990; 69: 995-1001.

6. James AL, Paré PD, Hogg JC. The mechanics of airway narrowing in asthma. Am Rev Respir Dis 1989; 139: 242-246.

7. Mitchell HW, Sparrow MP. Increased responsiveness to cholinergic stimulation of small compared to large diameter cartilaginous bronchi. Eur Respir J 1994; 7: 298- 305.

8. Wiggs BR, Moreno R, Hogg JC, Hilliam C, Paré PD. A model of the mechanics of airway narrowing. $J$ Appl Physiol 1990; 69: 849-860.

9. Mitchell HW, Willet KE, Sparrow MP. Perfused bronchial segment and bronchial strip: narrowing $v s$ isometric force by mediators. J Appl Physiol 1989; 66: 2704-2709.
10. Sparrow MP, Mitchell HW. Modulation by the epithelium of the extent of bronchial narrowing produced by substances perfused through the lumen. Br J Pharmacol 1991; 103: 1160-1164.

11. Mitchell HW, McFawn PK, Sparrow MP. Increased narrowing of bronchial segments from immature pigs. Eur Respir J 1992; 5: 207-212.

12. Hulsmann AR, Raatgeep HR, Bonta IL, Stijnen T, Kerrebijn $\mathrm{KF}$, de Jongste JC. The perfused human bronchiolar tube characteristics of a new model. J Pharmacol Methods 1992; 28: 29-34.

13. Martinez FD. Sudden infant death syndrome and small airway occlusion: facts and a hypothesis. Pediatrics 1991; 87: 190-198. 